\title{
Perspectives on personal protective equipment in acute care facilities during the COVID-19 pandemic
}

\author{
Josh Ng-Kamstra MDCM MPH, Henry T. Stelfox MD PhD, Kirsten Fiest PhD, John Conly MD, \\ Jeanna Parsons Leigh PhD
}

Cite as: CMAJ 2020 July 13;192:E805-9. doi: 10.1503/cmaj.200575; early-released June 25, 2020

A s the coronavirus disease 2019 (COVID-19) pandemic continues to grow, health care organizations have had to select appropriate personal protective equipment (PPE) for health care workers in the face of uncertainty and a strained supply chain. Although infection prevention and control experts have provided evidence-informed guidance, there has been substantial fear among health care workers that, owing to either policy or lack of supply, they may be left unduly exposed to transmission events of severe acute respiratory syndrome coronavirus 2 (SARS-CoV-2), the virus that causes COVID-19. ${ }^{1}$ Droplet and contact precautions with a bundle of activities including hand hygiene and use of gloves, gowns, eye protection and medical masks are typically recommended to protect against respiratory viruses. ${ }^{2}$ N95 respirator use is generally recommended during aerosol-generating medical procedures such as intubation. ${ }^{3}$

Do these recommendations provide the protection from COVID-19 that health care workers need? We analyze perspectives on hospital-based PPE to inform decision-making and dialogue during the COVID-19 pandemic.

\section{A history of current recommendations for PPE use by health care workers with respect to COVID-19}

Transmissibility and virulence of a respiratory virus are both considerations when selecting PPE. Whereas respiratory viruses such as rhinovirus or adenovirus tend to cause mild infections, SARSCoV-2 may cause severe or critical illness, with an increased mortality risk among older people and those with comorbidities. ${ }^{4}$ Deaths have occurred among health care workers, although at lower case-fatality rates than the general population. ${ }^{5}$ Further, the high death toll from COVID-19 in Canada has been driven by outbreaks at long-term care facilities, where patient management procedures and PPE availability have varied greatly. ${ }^{6}$ Given the risk of severe illness and nosocomial spread, strong efforts should be made to minimize the risk of viral transmission in health care settings.

When COVID-19 emerged in Wuhan, China, PPE used to treat patients was complex and extensive - in the context of an

\section{KEY POINTS}

- Guidelines for personal protective equipment (PPE) for the general care of patients with coronavirus disease 2019 (COVID-19) in acute care facilities recommend gloves, an isolation gown, eye protection, and a medical mask or $\mathrm{N} 95$ respirator.

- Given known transmission characteristics of severe acute respiratory syndrome coronavirus 2 (SARS-CoV-2), N95 respirators are required only in the context of aerosol-generating medical procedures.

- With a limited supply of N95 respirators, organizations can choose among various strategies to ensure sufficient availability of respirators, each with advantages and drawbacks.

- More complex PPE regimens do not necessarily provide greater protection, and some may increase risks of self-contamination during doffing.

- Hospitals can use an integrated knowledge translation approach to PPE research and policy-making to build trust, ensure that health care workers have confidence in their PPE, and to quickly adopt new scientific findings into practice.

unknown virus and limited information about its transmissibility, health care workers used double-gloving, full protective suits, goggles, surgical caps and $\mathrm{N} 95$ respirators. ${ }^{7}$ Despite these measures, thousands of health care workers acquired the virus. ${ }^{8}$ Many of these infections occurred early in the epidemic and most were likely community acquired. ${ }^{5}$ Guidelines from the US Centers for Disease Control and Prevention subsequently suggested that for general care of patients with COVID-19, basic PPE should include 4 components: gloves, an isolation gown, goggles or a disposable face shield, and a medical mask or N95 respirator. ${ }^{9}$ They suggested that a properly fitted $\mathrm{N} 95$ respirator was preferred, but if unavailable, a medical mask was appropriate for general care. At the same time, the World Health Organization and the Public Health Agency of Canada recommended reserving N95 respirators for aerosol-generating medical procedures and using medical masks in all other contexts. ${ }^{10-12}$ The Infectious Diseases Society of America recently released PPE guidelines assessed by the Grading of Recommendations Assessment, Development and Evaluation 
(GRADE) tool, which suggested that either a medical mask or N95 respirator may be used for care of patients with COVID-19 in the absence of aerosol-generating medical procedures. ${ }^{13}$

\section{Is SARS-CoV-2 primarily transmitted by droplets or aerosols in most settings?}

Patterns of transmission form the basis of guidelines for PPE usage. N95 respirators are recommended for aerosolized biohazards, whereas medical masks are recommended for droplets. ${ }^{14}$ The available evidence for primary modes of transmission of SARS-CoV-2 strongly supports droplet and contact spread. ${ }^{13}$ In most circumstances, aerosol-based transmission is not thought to play a major role. There is indirect evidence for this: the $R_{0}$ (number of secondary infections for each case) of aerosolized viruses is typically very high, estimated at greater than 10 for measles. ${ }^{15}$ By contrast, the $\mathrm{R}_{0}$ for COVID-19 is estimated to be between 2.2 and 2.7, comparable to influenza and other droplettransmitted viruses. ${ }^{16}$ The absence of aerosol transmission is further supported by the relatively low attack rate in households: about $10 \%$ of household contacts of cases become infected, much lower than would be expected with aerosol spread. ${ }^{17}$ When the virus is aerosolized in a laboratory setting using a 3-jet collision nebulizer, it can remain in aerosol form for several hours. However, these experimental conditions do not simulate aerosolgenerating medical procedures and are of little relevance to the clinical setting. ${ }^{18}$ A Chinese study found evidence of SARS-CoV-2 genetic material in the air in $35 \%$ of intensive care unit (ICU) samples, but all air samples were negative in Singaporean and Iranian settings, and no study has confirmed the presence of infectious viral particles in the air. ${ }^{19-21}$

\section{What evidence exists regarding the comparative effectiveness of medical masks versus $\mathrm{N} 95$ respirators?}

Considerable data are available on the measures necessary to prevent hospital transmission of SARS-CoV, the virus that causes SARS. Case-control studies suggested the importance of handwashing, gloves, gowns, eye protection and medical masks in preventing infection among health care workers in Hong Kong. ${ }^{22,23}$ However, practices for management of patients with SARS in 2002-2003 varied in different settings, with 1 Toronto site requiring double-gloving and gowning, caps, goggles, shoe covers and a properly fitted N95 respirator. ${ }^{24}$ Multiple reports documented SARS-CoV transmission to health care workers despite the use of $\mathrm{N} 95$ respirators, however. ${ }^{25,26}$

After SARS, evidence accrued showing that medical masks were no different from $\mathrm{N} 95$ respirators for preventing viral respiratory infections as a component of the PPE during routine clinical care. A systematic review in 2016 concluded that although N95 respirators have greater efficacy than medical masks on laboratory-based surrogate measures, medical masks performed as well as respirators for preventing acute respiratory illness in clinical settings. ${ }^{27} \mathrm{~A}$ large randomized controlled trial published in 2019 showed that in the outpatient setting, medical masks performed as well as $\mathrm{N} 95$ respirators in preventing laboratory-confirmed influenza. ${ }^{28}$

A systematic review on measures to decrease betacoronavirus transmission compared $\mathrm{N} 95$ respirators to no protection and, separately, medical masks to no protection. ${ }^{29}$ None of the studies were randomized. Although the pooled odds of transmission were lower in the respirator studies, no study has directly compared respirators with masks and so claims ${ }^{30}$ that respirators are superior to masks for general care are unfounded. Moreover, series have emerged in which large numbers of health care workers were unknowingly exposed to COVID-19; most used medical masks rather than respirators, and transmission occurred only when mask use was intermittent or omitted. ${ }^{31,32}$

\section{Which procedures may be aerosol generating?}

Guidelines recommend N95 or equivalent respirators for care during aerosol-generating medical procedures, although there is variation in the specific list of what should be considered truly aerosol-generating. ${ }^{13} \mathrm{~A}$ systematic review that included 10 studies of aerosol-generating medical procedures during the SARS epidemic found that tracheal intubation, noninvasive ventilation, tracheostomy and manual ventilation before intubation consistently increased risk to health care workers. ${ }^{33}$ Other procedures, such as nebulizer treatment, bronchoscopy and chest compressions, may also pose an increased risk. The studies included in this review were graded as low-quality evidence, but randomized or prospective data on whether masks or respirators should be used for each procedure are unlikely to emerge. Guidelines therefore tend to be more inclusive when listing aerosolgenerating medical procedures.

Whether caring for an ICU patient who is intubated and on a closed circuit requires the use of an N95 respirator merits specific attention. The risk of accidental ventilator tubing disconnection should be considered; this risk may be higher if the patient is being moved frequently, such as for prone ventilation. However, even if tubing becomes disconnected, there is no evidence that this event will lead to aerosolization of virus. A study in Taiwan during the SARS epidemic used polymerase chain reaction to test for the presence of aerosolized virus in the air surrounding an intubated patient; none was detected even after extubation. ${ }^{34}$ Despite the limitations of this single-patient study, it provides some reassurance that aerosol-based transmission may not play a substantial role during the regular care of the mechanically ventilated patient. The Surviving Sepsis Campaign COVID-19 guidelines recommend that for patients who have COVID-19 and are on closed circuit mechanical ventilation, medical masks should be used. ${ }^{35}$

\section{Approaches to managing a limited supply of N95 respirators}

During the novel influenza A ( $\mathrm{H} 1 \mathrm{~N} 1)$ pandemic, Canadian providers felt that appropriate PPE was readily available. ${ }^{36}$ The context of COVID-19 is much different. N95 respirators represent a sophisticated technology compared with medical masks, are more expensive and 
are in shorter supply. ${ }^{37}$ With exports dramatically decreased from China and increased global demand for N95 respirators, these products have become scarce despite post-SARS stockpiling., ${ }^{9,38,39}$

There is a risk that single-use N95 respirator supplies will be insufficient to last through the pandemic despite aggressive and innovative sourcing by governments and hospitals. Hospital policy can therefore take several approaches:

1. Limit N95 respirator use to aerosol-generating medical procedures and recommend medical mask use for interactions such as caring for the intubated patient

2. Ration N95 supply: some jurisdictions have limited provision of N95 masks to 1 per health care worker per day, per week, or until visibly soiled

3. Reprocess used N95 respirators via novel sterilization processes

4. Explore reusable $\mathrm{N} 95$ respirators that use cartridges or replaceable filters

Each option has advantages and disadvantages. The first is a simple approach that is supported by the Surviving Sepsis Campaign guidelines for COVID-19, but one that might not be accepted by all health care providers. The second is similarly simple to implement, but poses risks of self-contamination with the reuse of equipment designed to be disposable; Infectious Diseases Society of America guidelines try to mitigate this risk by suggesting that the respirator be covered by a face shield or medical mask. ${ }^{13}$ Third, there are guidelines from the World Health Organization and Centers for Disease Control and Prevention related to options for extended use or reprocessing as temporary measures for shortages of PPE, if other strategies have been exhausted. ${ }^{11,40}$ One manufacturer, $3 \mathrm{M}$, has acknowledged the use of vapourized hydrogen peroxide as a valid reprocessing method for $\mathrm{N} 95$ respirators. ${ }^{41}$ A recent National Institutes of Health study in preprint supports effective decontamination of N95 respirators without impairing function, ${ }^{42}$ and a large multicentre project is under way to further validate decontamination methods. ${ }^{43}$ Finally, reusable, cleanable respirators are an attractive option, but to date have not been studied in clinical settings and will likely require specialized hospital sterilization and reprocessing procedures. ${ }^{44}$

\section{What other considerations should guide choice of PPE in acute care settings?}

Unit setup may influence the type of PPE chosen. In hospitals where patients with COVID-19 are cared for on dedicated units (cohorted), and all care can be provided without doffing PPE, more complex PPE might be chosen, as fewer doffing episodes mitigate the increased risk of self-contamination while doffing complex PPE. ${ }^{45}$ In units where patients with COVID-19 are cared for alongside uninfected patients, or where nursing staff are required to doff before checking orders or documenting care, simpler PPE may lead to fewer errors in removing PPE and thus decrease the risk of self-contamination.

In cohorted units where PPE is worn for long periods, prolonged use of $\mathrm{N} 95$ respirators may have deleterious effects on some groups of health care workers; for example, impaired gas exchange and increased metabolic load with the use of respirators has been documented among healthy pregnant women. ${ }^{46}$ More broadly, increased airflow resistance leading to decreased tidal volumes, hypercarbia, subjective fatigue and facial dermatitis have all been reported with prolonged use of respirators. ${ }^{47-50}$

Real-world effectiveness of PPE may vary, especially during the early adoption of its use. Rates of self-contamination may be high before health care workers learn how to use a new PPE technique safely. ${ }^{51}$ Such learning is not automatic, and time for teaching, learning, use and reinforcement must be built into the workflow. The rapidity with which new PPE techniques can be safely taught remains unknown. Complex PPE regimens were taught, drilled and implemented for use in COVID-19 in China, ${ }^{7}$ as well as during the Ebola outbreak in $2014-2015 .{ }^{45,51}$ More is not necessarily better: for Ebola, critical errors remained more common in enhanced versus basic PPE regimens despite training. ${ }^{45}$ Furthermore, more complex regimens pose a greater time burden for donning and doffing. ${ }^{45}$ Increased donning and doffing errors for a complex regimen to purify respirators using powered air have also been documented in an experimental Canadian context. ${ }^{52}$ Having a dedicated person (i.e., a "buddy") to supervise doffing procedures and correct errors in real time may protect health care workers from self-contamination, particularly for more complex PPE regimens. ${ }^{14}$

\section{How should health care worker perspectives be integrated into organizational PPE decisions?}

Critical to choosing PPE regimens, but rarely explored, is how safe health care workers feel with the PPE regimen designated by their local hospital..$^{53}$ Individuals and organizations may interpret the literature differently, and may arrive at different conclusions as to which PPE is appropriate for a given context for a novel virus. A breakdown of trust and communication can lead to conflict, anxiety and worker absences. For example, in March 2020, some nurses and nursing groups across Canada cited occupational health and safety legislation, refusing to work without N95 respirators because they deemed doing so to be unsafe. ${ }^{54}$ In addition, the Canadian Union of Public Employees insisted that all hospital staff should have the choice to wear N95 respirators, ${ }^{55}$ despite good evidence showing they are not required in most settings.

Clear, streamlined and synthesized communication of the evidence underpinning organizational decisions on PPE use, as well as opportunities for health care workforce to engage and respond, are crucial and should be informed by the well-defined principles of knowledge translation. ${ }^{56,57}$ Upshur and colleagues' 2005 report on ethical considerations for pandemic planning emphasizes transparency, whereby the rationale for decisions should be open to scrutiny. ${ }^{58}$ When making decisions under conditions of uncertainty, it follows that honesty about what is and is not known is paramount.

The Canadian Federation of Nurses' Unions argues that the expertise of nurses should be leveraged in point-of-care risk assessments. ${ }^{59}$ Engaging multidisciplinary expertise earlier - in 
pandemic planning and in the drafting of occupational health and safety guidelines - maximizes the agency of health care professionals and allows for a more fulsome analysis of the literature than is possible at the bedside. It may also serve to ground infection control policy in pragmatism. This planning role is written into the Canadian Nurses' Association Code of Ethics. ${ }^{60}$

Engaging "knowledge users" from inception through to implementation of policy in this way is fundamental to integrated knowledge translation. The Canadian Institutes of Health Research emphasizes the dynamic and iterative nature of integrated knowledge translation; ${ }^{61}$ these features make it ideally suited to the rapidly changing knowledge environment of a pandemic. By putting the perspectives of health care workers at the centre of policy, organizations can build trust, improve communication and ensure that new recommendations are quickly implemented.

\section{Conclusion}

Guidelines about PPE are based on current understanding of how the SARS-CoV-2 virus is transmitted and provide a starting point for hospital infection prevention and control strategies during this pandemic. ${ }^{11}$ Answering questions such as how aerosols are generated, how limited supply of PPE can be managed, how care can be organized to optimize PPE use and how health care worker perspectives can be integrated into organizational decisions is central to protecting health care workers from SARS-CoV-2 and future pandemic pathogens. The likelihood that this virus will continue to circulate for months or years makes additional research more urgent and important than ever. Further understanding the basic science of aerosols in health care environments, investing in disruptive PPE technologies and fostering innovation in systems and pathways of care for patients with infectious diseases may help to protect patients and health care workers alike. Finally, using an integrated knowledge translation approach to policy development that includes health care workers in the planning and evaluation of PPE strategies will help to ensure that users of PPE can have confidence in it and use it effectively.

\section{References}

1. Thielking M. Frustrated and afraid about protective gear shortages, health workers are scouring for masks on their own. STAT news 2020 Mar. 18.

2. Guidance: infection prevention and control measures for healthcare workers in acute care and long-term care settings. Ottawa: Public Health Agency of Canada; 2010. Available: https://ipac-canada.org/photos/custom/OldSite/ pdf/101217newsEN_Final_Seasonal_Influenza-1.pdf (accessed 2020 Mar. 18).

3. Prevention strategies for seasonal influenza in healthcare settings: guidelines and recommendations. Atlanta: Centers for Disease Control and Prevention; 2018. Available: https://www.cdc.gov/flu/professionals/infectioncontrol/ healthcaresettings.htm (accessed 2020 Mar. 18).

4. Wu Z, McGoogan JM. Characteristics of and important lessons from the coronavirus disease 2019 (COVID-19) outbreak in China: summary of a report of 72314 cases from the Chinese Center for Disease Control and Prevention. JAMA 2020 Feb. 24 [Epub ahead of print]. doi: 10.1001/jama.2020.2648.

5. Report of the WHO-China Joint Mission on coronavirus disease 2019 (COVID-19). Geneva: World Health Organization; 2020.

6. Fisman D, Bogoch I, Lapointe-Shaw L, et al. Failing our most vulnerable: COVID-19 and Long-Term Care Facilities in Ontario. medRxiv 2020 Apr. 17. doi: 10.1101/2020.04.14.20065557.

7. The First Affiliated Hospital - Zhejiang University School of Medicine. Handbook of COVID-19 prevention and treatment. Hangzhou (China): The Jack Ma Foundation and Alibaba Foundation; 2020. Available: https://gmcc.alibabadoctor.com/ prevention-manual/detail?content_id=0 (accessed 2020 Mar. 18).
8. Wang J, Zhou M, Liu F. Reasons for healthcare workers infected with novel coronavirus disease 2019 (COVID-19) in China. J Hosp Infect 2020;105:100-1.

9. Interim infection prevention and control recommendations for patients with suspected or confirmed coronavirus disease 2019 (covid19) in healthcare settings. Atlanta: Centers for Disease Control and Prevention; 2020. Available: https://www.cdc.gov/coronavirus/2019- ncov/infection-control/control -recommendations.html

10. Coronavirus disease (COVID-19) technical guidance: infection prevention and control / WASH. Geneva: World Health Organization; 2020. Available: www.who. int/emergencies/diseases/novel-coronavirus-2019/technical-guidance/infection -prevention-and-control (accessed 2020 Mar. 18).

11. Rational use of personal protective equipment for coronavirus disease (COVID-19) and considerations during severe shortages: interim guidance. Geneva: World Health Organization; 2020.

12. Infection prevention and control for COVID-19: second interim guidance for acute healthcare settings. Ottawa: Public Health Agency of Canada; 2020. Available: www.canada.ca/en/public-health/services/diseases/2019-novel -coronavirus-infection/health-professionals/infection-prevention-control-covid -19-second-interim- guidance.html\#a8.7 (accessed 2020 May 20).

13. Lynch J, Davitkov P, Anderson D, et al. Infectious Diseases Society of America Guidelines on infection prevention for health care personnel caring for patients with suspected or known COVID-19. Arlington (VA): Infectious Disease Society of America; 2020. Available: www.idsociety.org/practice- guideline/covid -19-guideline-infection-prevention (accessed 2020 May 17).

14. Conly J, Eremin S, Pessoa-Silva C, et al., editors. Infection prevention and control of epidemic- and pandemic-prone acute respiratory infections in health care. Geneva: World Health Organization; 2014.

15. Guerra FM, Bolotin S, Lim G, et al. The basic reproduction number (R0) of measles: a systematic review. Lancet Infect Dis 2017;17:e420-8.

16. Sanche S, Lin YT, Xu C, et al. High contagiousness and rapid spread of severe acute respiratory syndrome coronavirus 2. Emerg Infect Dis 2020;26(7).

17. Burke RM, Midgley CM, Dratch A, et al. Active monitoring of persons exposed to patients with confirmed COVID-19 - United States, January-February 2020. MMWR Morb Mortal Wkly Rep 2020;69:245-6.

18. van Doremalen N, Bushmaker T, Morris DH, et al. Aerosol and surface stability of SARS-CoV-2 as compared with SARS-CoV-1. N Engl J Med 2020;382:1564-7.

19. Ong SWX, Tan YK, Chia PY, et al. Air, surface environmental, and personal protective equipment contamination by severe acute respiratory syndrome coronavirus 2 (SARS-CoV-2) from a symptomatic patient. JAMA 2020;323:1610-2.

20. Guo ZD, Wang ZY, Zhang SF, et al. Aerosol and surface distribution of severe acute respiratory syndrome coronavirus 2 in hospital wards, Wuhan, China, 2020. Emerg Infect Dis 2020;26(7).

21. Faridi S, Niazi S, Sadeghi K, et al. A field indoor air measurement of SARS-CoV-2 in the patient rooms of the largest hospital in Iran. Sci Total Environ 2020;725:138401.

22. Lau JT, Fung KS, Wong TW, et al. SARS transmission among hospital workers in Hong Kong. Emerg Infect Dis 2004;10:280-6.

23. Seto WH, Tsang D, Yung RW, et al. Effectiveness of precautions against droplets and contact in prevention of nosocomial transmission of severe acute respiratory syndrome (SARS). Lancet 2003;361:1519-20.

24. Cheng VC, Chan JF, To KK, et al. Clinical management and infection control of SARS: lessons learned. Antiviral Res 2013;100:407-19.

25. Cluster of severe acute respiratory syndrome cases among protected health-care workers - Toronto, Canada, April 2003. MMWR Morb Mortal Wkly Rep 2003;52:433-6.

26. Chen YC, Chen PJ, Chang SC, et al. Infection control and SARS transmission among healthcare workers, Taiwan. Emerg Infect Dis 2004;10:895-8.

27. Smith JD, MacDougall CC, Johnstone J, et al. Effectiveness of N95 respirators versus surgical masks in protecting health care workers from acute respiratory infection: a systematic review and meta-analysis. CMAJ 2016;188:567-74.

28. Radonovich LJ, Simberkoff MS, Bessesen MT, et al. N95 respirators vs medical masks for preventing influenza among health care personnel: a randomized clinical trial. JAMA 2019;322:824-33.

29. Chu DK, Akl E, Duda S, et al. Physical distancing, face masks, and eye protection to prevent person-to-person transmission of SARS-CoV-2 and COVID-19: a systematic review and meta-analysis. Lancet 2020 June 1 [Epub ahead of print]. doi: 10.1016/S0140-6736(20)31142-9.

30. Mandavilli A. Medical workers should use respirator masks, not surgical masks. New York Times 2020 June 1.

31. Ng K, Poon BH, Kiat Puar TH, et al. COVID-19 and the risk to health care workers: a case report. Ann Intern Med 2020;172:766-7.

32. Heinzerling A, Stuckey MJ, Scheuer T, et al. Transmission of COVID-19 to health care personnel during exposures to a hospitalized patient - Solano County, California, February 2020. MMWR Morb Mortal Wkly Rep 2020;69:472-6.

33. Tran K, Cimon K, Severn M, et al. Aerosol generating procedures and risk of transmission of acute respiratory infections to healthcare workers: a systematic review. PLoS One 2012; 7:e35797. 
34. Tsai YH, Wan GH, Wu YK, et al. Airborne severe acute respiratory syndrome coronavirus concentrations in a negative-pressure isolation room. Infect Control Hosp Epidemiol 2006;27:523-5.

35. Alhazzani W, Moller MH, Arabi YM, et al. Surviving Sepsis Campaign: guidelines on the management of critically ill adults with coronavirus disease 2019 (COVID-19). Intensive Care Med 2020;46:854-87.

36. Mitchell R, Ogunremi T, Astrakianakis G, et al. Impact of the 2009 influenza A (H1N1) pandemic on Canadian health care workers: a survey on vaccination, illness, absenteeism, and personal protective equipment. Am J Infect Control 2012;40:611-6.

37. Patel A, D'Alessandro MM, Ireland KJ, et al. Personal protective equipment supply chain: lessons learned from recent public health emergency responses. Health Secur 2017;15:244-52.

38. Mendoza M, Linderman J. Imports of medical supplies plummet as demand in US soars. Associated Press 2020 Mar.

39. Section 2: Evaluation of the National Emergency Stockpile System (NESS) background. Ottawa: Public Health Agency of Canada; 2012. Available: https://canada.ca/en/public-health/corporate/mandate/about-agency/office -evaluation/evaluation-reports/evaluation-national-emergency-stockpile -system/background-context.html\#background-2 (accessed 2020 May 17).

40. Decontamination and reuse of filtering facepiece respirators. Atlanta: Centers for Disease Control and Prevention; 2020. Available: www.cdc.gov/ coronavirus/2019-ncov/hcp/ppe-strategy/decontamination-reuse-respirators. html (accessed 2020 May 10).

41. Decontamination methods for $3 \mathrm{M}$ filtering facepiece respirators such as N95 respirators. Saint Paul (MN): 3M; 2020. Available: https://multimedia.3m.com/ $\mathrm{mws} /$ media/18248690/decontamination-methods-for-3m-filtering-facepiece -respirators-technical-bulletin.pdf (accessed 2020 May 20).

42. Fischer R, Morris D, van Doremalen N, et al. Assessment of N95 respirator decontamination and re-use for SARS-CoV-2. medRxiv 2020 Apr. 24. doi: 10.1101/2020.0 4.11.20062018.

43. DeMaND Study Partners. DeMaND study. Stanford (CA): Stanford University; 2020. Available: https://stanfordmedicine.app.box.com/s/s6niip404em 07 coszrciumjlyneyd6ft (accessed 2020 June 1).

44. De Patie M. Manitoba business busy producing $500 \mathrm{~K}$ reusable N95 masks. CTV News 2020 May 9. Available: https://winnipeg.ctvnews.ca/manitoba -business-busy-producing-500k-reusable- n95-masks-1.4932497 (accessed 2020 May 17).

45. Casalino E, Astocondor E, Sanchez JC, et al. Personal protective equipment for the Ebola virus disease: a comparison of 2 training programs. Am J Infect Control 2015;43:1281-7.
46. Tong PS, Kale AS, Ng K, et al. Respiratory consequences of N95-type mask usage in pregnant healthcare workers-a controlled clinical study. Antimicrob Resist Infect Control 2015;4:48.

47. Lee HP. Wang de Y. Objective assessment of increase in breathing resistance of N95 respirators on human subjects. Ann Occup Hyg 2011;55:917-21.

48. Roberge RJ, Coca A, Williams WJ, et al. Physiological impact of the N95 filtering facepiece respirator on healthcare workers. Respir Care 2010;55:569-77.

49. Li Y, Tokura H, Guo YP, et al. Effects of wearing N95 and surgical facemasks on heart rate, thermal stress and subjective sensations. Int Arch Occup Environ Health 2005;78:501-9.

50. Foo CC, Goon AT, Leow YH, et al. Adverse skin reactions to personal protective equipment against severe acute respiratory syndrome - a descriptive study in Singapore. Contact Dermatitis 2006;55:291-4.

51. Suen LKP, Guo YP, Tong DWK, et al. Self-contamination during doffing of personal protective equipment by healthcare workers to prevent Ebola transmission. Antimicrob Resist Infect Control 2018;7:157.

52. Zamora JE, Murdoch J, Simchison B, et al. Contamination: a comparison of 2 personal protective systems. CMAJ 2006;175:249-54.

53. Fix GM, Reisinger HS, Etchin A, et al. Health care workers' perceptions and reported use of respiratory protective equipment: a qualitative analysis. $\mathrm{Am} \mathrm{J}$ Infect Control 2019;47:1162-6.

54. Blackwell T. Canadian nurses treating COVID-19 patients cite unsafe-work laws to demand N95 masks. National Post [Toronto] 2020 Mar. 31.

55. Weeks C. Ontario, Alberta change policy limiting N95 masks as health-care workers demand greater access. The Globe and Mail [Toronto] 2020 Apr. 2.

56. Choi BC. Understanding the basic principles of knowledge translation. J Epidemiol Community Health 2005;59:93.

57. Jull J, Giles A, Graham ID. Community-based participatory research and integrated knowledge translation: advancing the co-creation of knowledge. Implement Sci 2017;12:150.

58. Upshur R, Faith K, Gibson J, et al. Stand on guard for thee: ethical considerations in preparedness planning for pandemic influenza. Toronto: University of Toronto Joint Centre for Bioethics; 2005.

59. Position statement on COVID-19. Ottawa: Canadian Federation of Nurses Unions; 2020. Available: https://nursesunions.ca/position-statement-on-covid -19/ (accessed 2020 May 10).

60. Nurses' ethical considerations in a pandemic or other emergency. Ottawa: Canadian Nurses Association; 2008.

61. Knowledge translation at CIHR. Ottawa: Canadian Institutes for Health Research; 2016. Available: https://cihr-irsc.gc.ca/e/29418.html\#1 (accessed 2020 May 20).
Competing interests: Henry T. Stelfox was supported by an Embedded Clinician Researcher Award from the Canadian Institutes of Health Research (CIHR). John Conly holds grants from $\mathrm{CIHR}$ on acute and primary care preparedness for COVID-19 in Alberta, Canada, and was the primary local Investigator for a Staphylococcus aureus vaccine study funded by Pfizer, for which all funding was provided only to the University of Calgary. He also received support from the Centres for Disease Control and Prevention to attend an Infection Control Think Tank Meeting. No other competing interests were declared.

This article has been peer reviewed.

Affiliations: Department of Critical Care Medicine (Ng-Kamstra, Stelfox, Fiest), Cumming School of Medicine, University of Calgary and Alberta Health Services; Departments of Community Health Sciences and O'Brien Institute for Public Health (Stelfox, Fiest), Psychiatry and Hotchkiss Brain Institute (Fiest), Medicine (Conly), Pathology and Laboratory Medicine (Conly) and Microbiology, Immunology, and Infectious Diseases, and Snyder Institute for Chronic Diseases (Conly), Cumming School of Medicine, University of Calgary, Calgary, Alta.; Faculty of Health (Parsons Leigh), School of Health Administration, and Department of Critical Care Medicine, Faculty of Medicine (Parsons Leigh), Dalhousie University, Halifax, NS

Contributors: Josh Ng-Kamstra conducted the analysis and drafted the manuscript. Henry T. Stelfox, Kirsten Fiest and John Conly interpreted the data and critically revised the manuscript for important intellectual content. Jeanna Parsons Leigh designed the study, interpreted the data, drafted and critically revised the manuscript. All of the authors read and approved the final version to be published and agreed to be accountable for all aspects of the work.

Funding: This article is funded by the Canadian Institutes of Health Research Canadian 2019 Novel Coronavirus (COVID-2019) Rapid Research Funding Opportunity - Operating Grant (Grant number RN420046 - 439965) to J.P.L.

Correspondence to: Jeanna Parsons Leigh, j.parsonsleigh@dal.ca 